\title{
Authentic learning with technology for professional development in vaccine management
}

\author{
Hanna Teräs \\ Murdoch University, Perth, Australia \\ Ümit Kartoğlu \\ World Health Organization, Geneva, Switzerland
}

\begin{abstract}
Online professional development (OPD) is gaining increasing popularity. However, online learning environments are not always considered effective venues for supporting authentic learning experiences, and the suitability of OPD for practical learning has not been widely explored. This case study paper presents findings of a pilot implementation of an OPD program in vaccine management designed according to the pedagogical principles of authentic learning, using a range of educational technologies as cognitive tools. The study examines how the authentic learning design and the technologies used affect the participants' learning experience, experience of authenticity and the perceived impact of the course on professional learning. Data was collected through observations, an online postcourse survey and interviews with the participants. A thematic content analysis was conducted. The findings suggest the pedagogical framework of authentic e-learning provides useful guidelines for the design of fully online, yet active and practice-driven, professional development that is also perceived as authentic by the participants. Using online education technologies as cognitive tools can support the creation of an authentic learning environment where practical, transferable professional skills can be acquired. Achieving this requires careful consideration of accessibility and usability issues and ensuring that the technologies used serve an authentic purpose.
\end{abstract}

\section{Introduction}

Online professional development (OPD) programs are becoming increasingly popular for maintaining and developing professional expertise (Bates, Phalen, \& Moran, 2016; Bradley, Rachal, \& Harper, 2014). Several benefits have been associated with OPD programs: they are easier to fit in the busy schedules of the professionals, they provide access to otherwise unavailable resources and support, and they tend to be more cost-effective to run and participate in than face-to-face professional development (Bates et al., 2016; Bradley et al., 2014). However, delivering professional development online is not an easy task. Especially interaction and collaboration are often difficult to achieve in OPD (Liu, 2012). OPD is sometimes seen as better suited for theoretical content-oriented learning than practical, hands-on professional learning (Kyalo \& Hopkins, 2013), and online learning environments are not traditionally considered as venues for promoting authentic learning experiences (Herrington, Reeves, \& Oliver, 2010).

This case study describes outcomes of a pilot implementation of an OPD program in vaccine management that seeks to promote authentic, collaborative, practice-oriented learning with immediate application and a high degree of collegial support. This study aims to answer three research questions:

(1) How did the authentic e-learning design and the technologies used in the course impact on the learning experience of the participants?

(2) What was the participants' experience of authenticity on the course?

(3) What was the perceived impact of the course on the professional development of the participants and what factors contributed to it?

The data was collected through observations during the implementation, an online post-course survey and interviews with the participants 3-6 months after the completion of the program. The findings are used as a basis for a set of initial design recommendations and lessons learned that are of interest to professional development providers, educational designers, teachers, mentors and education technology developers who are interested in designing and implementing OPD programs that aim at a practical and authentic professional learning experience. 


\section{What is authenticity in online professional development?}

Continuous professional development is widely recognised across professions as a necessary part of maintaining and developing professional expertise (Garet, Porter, Desimone, Birman, \& Yoon, 2001; Webster-Wright, 2009). Increasingly, professional development programs are provided online. Unfortunately, professional development endeavours, regardless of whether they are enabled online, faceto-face or in a blended mode, do not always result in the desired outcomes. Although there is a relatively wide consensus within the educational research community that successful professional development is active, social and practice-related, many professional learning interventions are still based on didactic information delivery and remain separated from engagement with authentic work experiences (WebsterWright, 2009). Consequently, the impact of professional development on actual changes in attitudes, behaviours and practice often remains low (Salmon \& Wright, 2014). Petraglia (2009) underlines the core of the problem by pointing out that without the ability to bring the information into practice and apply it to relevant contexts, the knowledge is useless. He argues that such information lacks authenticity that "enables individuals to understand, emotionally and cognitively, how information can relate to their everyday existence” (p. 176).

Authenticity can thus be seen as a key ingredient in successful OPD. Although authenticity in learning can be understood in several ways, it is often associated with learning approaches that emphasise realism, real-world relevance and orientation to practice. Authenticity is closely linked with elements of experiential learning (Kolb, 1984), such as active participation, reflection and experimentation using problem-solving skills, as well as the notion of learning knowledge and skills in realistic contexts as outlined in the theory of situated learning (Brown, Collins, \& Duguid, 1989). It is also associated with constructivist theories in that students are seen as active learners who learn through knowledge construction and meaning making. Moreover, the idea of authentic learning typically involves students' engagement in real-life situations and materials and practising actual skills rather than memorising factual disciplinary knowledge (Bozalek et al., 2013). Gulikers, Bastiaens, and Kirschner (2004) see authenticity in professional education as a situation that resembles a student's professional practice. Yeoman (2012) defines it as learning that is "facilitated through an action learning process of real-world and complex problems” (p. 298). Authentic learning has also been studied in association with project-oriented problem-based learning (Husnin, Din, Karim, Norman, \& Hamdan, 2013) as well as collaborative and progressive inquiry learning (Valtonen et al., 2015).

Consequently, authentic learning is commonly associated with learning environments that involve handson practice, on-site visits and observations, work placements and the like (Herrington et al., 2010). Perhaps for these reasons it has not yet been widely studied in the context of OPD. Indeed, OPD is still often seen by participants as theoretical and unsuited for practical subjects (see, e.g., Baran \& Cagiltay, 2006; Kyalo \& Hopkins, 2013). Typically, OPD programs consist of content delivery in the form of weekly readings or video lectures, quizzes and individual assignments, which is an electronic replica of the traditional academic learning setting.

Herrington et al. (2010) take a different approach to authenticity in e-learning in claiming that the cognitive realism of the learning environment is of a far greater importance than the physical realism. Herrington and Oliver (2000) introduce a pedagogical model of authentic e-learning based on critical characteristics of situated learning. This model was used as the design framework for the vaccine management course. In the following section we describe in further detail how the principles of the authentic e-learning model guided the learning design of the course, as well as how technologies were introduced as cognitive tools for the participants to use for different learning purposes. However, any education professional who has been involved in developing a new educational intervention will be able to tell that the intentions of the design and the actual outcomes may turn out very differently. Van den Akker (2003) distinguishes between the intended, the implemented and the attained curriculum: what it sets out to do, how it is actually used in practice and what the outcomes of it are. Authenticity and realism may be the intention of the course design and the choice of pedagogies, tools and technologies are informed by this intention, but it is crucially important to study the attained course design in order to be able to determine the effectiveness of the design choices. Gulikers, Bastiaens, Kirschner, and Kester (2008) argue that for authentic learning to reach its potential, it has to be perceived as authentic by the students rather than just by the teachers and educational designers. This view is in line with Petraglia (1998), who contends that contemporary constructivist learning theory does not automatically prescribe 
authenticity: designers inevitably create learning environments that reflect their own views of what is authentic. Rather, the learner's perception of authenticity is critically important for his/her learning because learning is embedded in our experience of the world, not in formal information that can be simply delivered with the expectation that it will be acquired (Petraglia, 1998). This observation serves as the starting point for the research task at hand.

\section{Course design}

The context of the study is e-VVM, an international, online professional development course in vaccine management offered by the World Health Organization (2002) and EPELA (Extensio et Progressio Authentic eLearning, http://epela.net/epela_web/evvm.html). The e-VVM course is intended for representatives of national immunisation programs as well as pharmaceutical and vaccine industry experts and its purpose is to develop vaccine management skills using VVMs. A VVM is a label, containing a heat-sensitive material, which is placed on a vaccine vial to register cumulative heat exposure over time. The VVM indicates whether the vaccines have been damaged by heat. It thus helps to reduce vaccine wastage and facilitates the management of vaccine stocks.

Upon completing the course, the participants should be able to work confidently with VVMs and use their newly acquired skills to make decisions, analyse factors, make recommendations and develop procedures. The distribution of the course's learning objectives across the cognitive process dimensions is given in Table 1 (based on Bloom, Engelhart, Furst, Hill, \& Krathwohl 1956; Anderson, Krathwohl, \& Bloom 2001).

Table 1

e-VVM course objectives distribution by cognitive process and knowledge dimensions

\begin{tabular}{|c|c|c|c|c|c|c|}
\hline \multirow{2}{*}{$\begin{array}{l}\text { Knowledge } \\
\text { dimensions }\end{array}$} & \multicolumn{6}{|c|}{ Cognitive process dimensions } \\
\hline & Remembering & Understanding & Applying & Analysing & Evaluating & Creating \\
\hline $\begin{array}{l}\text { Factual } \\
\text { knowledge }\end{array}$ & & 1 & & & & \\
\hline $\begin{array}{l}\text { Conceptual } \\
\text { knowledge }\end{array}$ & & & & & 1 & \\
\hline $\begin{array}{l}\text { Procedural } \\
\text { knowledge }\end{array}$ & & & 1 & 1 & 4 & 1 \\
\hline $\begin{array}{l}\text { Meta- } \\
\text { cognitive } \\
\text { knowledge }\end{array}$ & & 1 & & & 1 & 2 \\
\hline
\end{tabular}

Most of the learning objectives fall under the higher cognitive skills of evaluating and creating, whereas the role of memorising content is minimal. These learning objectives are practice-oriented and the skills learned must be directly transferable in the participants' work contexts. Therefore, the challenge was to develop an OPD program that, instead of delivering theoretical content, would be authentic, practical and realistic. The pedagogical model of authentic learning (Herrington et al., 2010) provides a design framework for situated, real-life oriented online learning, and this framework was operationalised to inform the learning design of the course. In accordance with the authentic e-learning model, technologies in the course were used as cognitive tools for problem solving, collaboration and creation, rather than primarily for content delivery (Jonassen \& Reeves, 1996).

The e-VVM course invites participants to interact and learn within a sophisticated simulation of a vaccine cold chain. For 9 weeks, participants and mentors travel virtually from one level to another in the vaccine supply chain. The course includes short expert videos and reference materials about critical content. The most important learning opportunities are enabled via authentic tasks. These tasks are arranged mainly as group activities to promote collaborative learning. Self, peer, and expert review are important aspects of assessment. Mentors provide feedback and assistance to the participants. Participants also work with real VVMs (sent by WHO under cold chain conditions); they expose these VVMs to different temperature conditions as experiments and report back to the group about their findings and conclusions. Following 5 weeks of virtual visits, participants are introduced as a group to a real client so that together with their peers as consultants they analyse a real-world cold chain challenge and make recommendations to the client regarding the presented situation. There are no specific lectures or readings tied to assignments, but 
participants are guided to review appropriate documents and view selected videos from the document and video libraries to support their learning. The activities spread over 9 weeks without any break. The course proceeds chronologically in a way that resembles a real-world situation. The individual and group tasks as well as facilitation are paced accordingly. The flow and details of the course are illustrated in Figure 1.

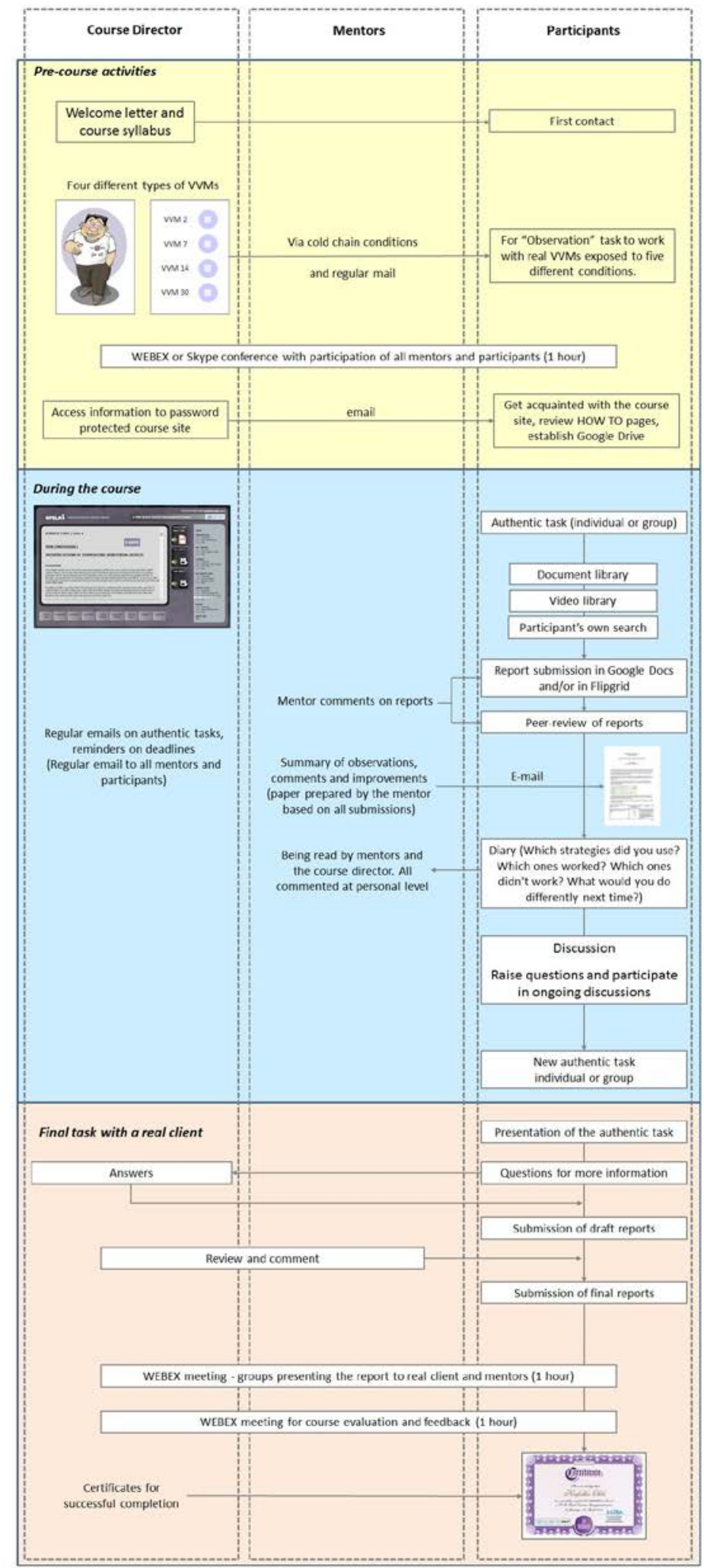

Figure 1. e-VVM course flow 
Herrington et al. (2010) introduce nine design principles that can be used to guide an authentic learning design (Table 2). Further, Jonassen and Reeves (1996) differentiate between learning from technology, where technology is used for content delivery, and learning with technology, where it is used as cognitive tools that are given to the learners to use for constructing knowledge, solving problems, collaborating and representing their knowledge to others. Authentic learning assumes the latter approach. In the e-VVM course, the virtual learning environment consists of a variety of digital technologies that aim to support the authentic learning experience in different ways. Table 2 illustrates how the authentic design principles were instantiated in the e-VVM course and which technologies were used. Table 3 explains in further detail the pedagogical purpose of each technology and how it was designed to be used.

Table 2

Examples of how authentic learning principles are instantiated in e-VVM course and technologies were used to promote them

\begin{tabular}{|c|c|c|}
\hline Authentic learning principle & How the principle was used & Technologies \\
\hline $\begin{array}{l}\text { Authentic context similar to the } \\
\text { context where the knowledge } \\
\text { will be used in real life. }\end{array}$ & $\begin{array}{l}\text { The vaccine supply chain is } \\
\text { represented through virtual visits } \\
\text { starting with the international }\end{array}$ & $\begin{array}{l}\text { EPELA environment, video } \\
\text { library, document library, VVM } \\
\text { cards }\end{array}$ \\
\hline
\end{tabular}

Authentic tasks which are as complex and ill-defined as real-world problems tend to be, instead of being broken down to oversimplified, clearly defined chunks

Access to expert performances and modelling of processes

Multiple perspectives instead of a single textbook or a clearly defined and restricted linear learning path

Collaborative construction of knowledge inherently built in the learning tasks rather than introduced as an additional extra

Opportunities for reflection shipments down to taking vaccines beyond $8^{\circ} \mathrm{C}$ for outreach activities.

Practices and approaches that experts/professionals would use are included in the course. All tasks are designed from real life problems notified by countries to WHO as well as observed by mentors during duty travels. Expert videos specifically produced for this course are offered through video library. Both videos and documents reflect multiple perspectives rather than providing a single answer. Resources also include nice-to-know information and links to other sources to help participants understand the broader contexts.

Regardless of individual or group type of work, participants have access to each other's work and comment on it. Individuals and groups create reports and recommendations as well as mind maps, flow charts and decision trees for processes these documents are now in use in the field.

Participants keep a diary to reflect on authentic tasks, their learning and approaches to solve problems. Diary entries are made following completion of the tasks, peer review and mentor comments, thus enabling participants to critically look at how they would approach the same problem in the future.
Google Drive, WebEx, VVM cards

Video library, document library

Video library, document library, discussion forums

Skype, discussion forums, Google Drive, Flipgrid

Diaries, scavenger hunt blog 


\begin{tabular}{lll}
\hline $\begin{array}{l}\text { Opportunities for articulating } \\
\text { one's growing knowledge }\end{array}$ & $\begin{array}{l}\text { Diaries, Flipgrid videos and } \\
\text { course director's one-on-one } \\
\text { interactions with participants } \\
\text { about their diary entries provide } \\
\text { articulation opportunities. }\end{array}$ & $\begin{array}{l}\text { Diaries, Flipgrid, discussion } \\
\text { forums, WebEx }\end{array}$ \\
$\begin{array}{l}\text { Scaffolding and coaching } \\
\text { instead of direct instruction } \\
\text { participants need them. They are } \\
\text { reachable via Skype, email and } \\
\text { other means. In each authentic } \\
\text { task, mentors provide comments }\end{array}$ & $\begin{array}{l}\text { Discussion forums, Skype, email, } \\
\text { within 24 hours. }\end{array}$ & \\
$\begin{array}{l}\text { Authentic assessment is } \\
\text { embedded within the tasks. }\end{array}$ & Diaries, discussion forums, \\
$\begin{array}{l}\text { embedded in the learning } \\
\text { process rather than introduced }\end{array}$ & $\begin{array}{l}\text { Products resulting from these } \\
\text { tasks include reports, peer } \\
\text { separately }\end{array}$ & \\
& $\begin{array}{l}\text { reviews and reflections in diaries, } \\
\text { presentations, and discussion } \\
\text { entries. These are used to assess } \\
\text { the participants' performance and } \\
\text { learning. }\end{array}$ & \\
\hline
\end{tabular}

Table 3

Tools/technologies used in the e-VVM course design and their pedagogical purposes

\begin{tabular}{|c|c|}
\hline Tool/technology & Pedagogical purpose \\
\hline EPELA environment & $\begin{array}{l}\text { Developed using a design-based approach as a platform to integrate } \\
\text { authentic learning principles. Currently hosts two e-learning courses offered } \\
\text { by the WHO. Its user-friendliness was studied during initial design of the } \\
\text { platform and through evaluations of the first e-learning course offered } \\
\text { through this platform (Vesper, Herrington, Kartoglu, \& Reeves, 2015). The } \\
\text { platform integrates virtual steps in the vaccine supply chain with the } \\
\text { authentic tasks/activities as well as resources and tools. }\end{array}$ \\
\hline Video library (EPELA) & $\begin{array}{l}\text { Many authentic tasks are introduced in a video format, presenting the } \\
\text { problems at hand. In addition, the video library provides expert videos } \\
\text { specifically produced for this course as well as technical videos on VVM. } \\
\text { They provide access to expert performances and modelling of processes. }\end{array}$ \\
\hline $\begin{array}{l}\text { Document library } \\
\text { (EPELA) }\end{array}$ & $\begin{array}{l}\text { Printed materials in the form of scientific papers, books, book chapters and } \\
\text { peer-reviewed articles are made accessible to course participants through an } \\
\text { online library. As for each authentic task, mentors suggest specific } \\
\text { documents that would help in solving the problem. Documents included in } \\
\text { the library reflect multiple perspectives rather than clearly defined and } \\
\text { restricted linear instructions. }\end{array}$ \\
\hline Diaries (EPELA) & $\begin{array}{l}\text { At the end of each virtual visit, participants are asked to reflect on what they } \\
\text { have learned and respond to questions using an online diary that only each } \\
\text { individual and the course director and mentors can access. In addition to the } \\
\text { task reports, diaries are also used for authentic evaluation. Each diary entry } \\
\text { is followed up by the course director with feedback to the participant via } \\
\text { email. }\end{array}$ \\
\hline $\begin{array}{l}\text { Discussion forum } \\
\text { (EPELA) }\end{array}$ & $\begin{array}{l}\text { The EPELA platform provides an online discussion forum where } \\
\text { participants can pose questions to other participants and mentors. Mentors } \\
\text { also pose questions - often based on real-life situations they are } \\
\text { experiencing in their own practice and work so as to challenge participants. } \\
\text { This tool supports the collaborative construction of knowledge. }\end{array}$ \\
\hline Skype & $\begin{array}{l}\text { Skype facilitates interaction for group assignments as well as participants' } \\
\text { engagement with mentors on one-on-one basis. }\end{array}$ \\
\hline VVM cards & $\begin{array}{l}\text { Participants work with real tools and run experiments. Participants are } \\
\text { required to expose VVM cards to different temperatures, observe the } \\
\text { changes throughout the course and report on their findings and conclusions } \\
\text { to the group at the end of the course. }\end{array}$ \\
\hline
\end{tabular}




\begin{tabular}{ll}
\hline Flipgrid & $\begin{array}{l}\text { Flipgrid supports articulation. It is used for the introduction of mentors and } \\
\text { participants about their expectations from the course as well as for one of } \\
\text { the authentic tasks. Participants are asked to record their responses in a }\end{array}$ \\
Flipgrid video ( 90 seconds max.). \\
The blog is used to enhance learning especially through increasing \\
observation skills on items related to VVMs. Participants are given a list of \\
situations and are asked to photograph these within their work environment \\
and post them along with story behind each photograph. \\
WebEx is used initially to facilitate the introduction of mentors and \\
participants before the course starts, and as a conference platform for the \\
final task for the groups to present their work. \\
Emails are used mainly by the course director for sending reminders to the \\
group on forthcoming tasks and deadlines. Mentors' feedback on the \\
authentic tasks is also communicated to the participants via email. \\
Google Drive is used for individual and groups tasks. It is organised with \\
folders and subfolders identical to the flow of the course and tasks. \\
Participants have access to all submissions and have to comment on each \\
other's work. Mentors also comment on each submission and comments in \\
the same platform. This facilitates the collaborative construction of \\
knowledge and provides a platform for scaffolding and mentoring.
\end{tabular}

As the above tables illustrate, the learning environment design in the e-VVM course goes beyond a traditional learning management system and introduces a wide range of digital technologies to be used as cognitive tools for problem-solving, collaborative knowledge construction and communication. The purpose of this design choice was to shift the focus from the content to the authentic tasks and collaboration, and promote learning by doing rather than learning by acquiring information.

\section{Data collection and analysis}

The present study is a classic case study in that it "consists of an in-depth inquiry into a specific and complex phenomenon (the 'case'), set within its real-world context” (Yin, 2013, p. 321). The “complex phenomenon" in the present study is the online professional learning experience of the e-VVM course participants. More specifically, the study seeks to answer the following research questions:

(1) How did the authentic e-learning design and the technologies used in the course impact on the learning experience of the participants?

(2) What was the participants' experience of authenticity on the course?

(3) What was the perceived impact of the course on the professional development of the participants and what factors contributed to it?

The central role of the authentic context in a case study leads to a myriad of variables of interest, uncontrollability of the research setting and an unclear boundary between the phenomenon itself and the context in which it occurs (Yin, 1999). A qualitative approach was employed in order to achieve a deep and detailed understanding of the complex phenomenon. The data was collected through observations in the virtual learning environment, a post-course online survey (SurveyMonkey), and semi-structured interviews with the participants. Under the WHO Ethics Review Committee Rules of Procedures, no formal ethics review was required for the study. The observations took place during the entire duration of the implementation and encompassed the discussion forums, synchronous group meetings via Skype and WebEx, Flipgrid, scavenger hunt blog and the final group presentations via WebEx. The observations were conducted in a transparent manner: the participants were aware of the presence of the researcher who also participated in the online communications, establishing rapport by meeting and conversing with the participants through the technologies used in the course. The post-course survey was completed immediately after the course. All eight participants who completed the beta version of the course responded to the survey. The interviews were conducted 3-6 months after the completion of the course. Data was collected at different points of the implementation to ensure a holistic picture of the participants' experience during the course as well as the perceived impact after the course was over. 
The interviews were conducted via Skype and they were recorded and transcribed. The duration of the interviews varied between 30 and 45 minutes. Seven of the eight participants volunteered to be interviewed. The interview questions encouraged the respondents to share their experiences regarding different aspects of the course, such as engaging with the course tasks and content, using different technologies, working in teams and using their newly acquired skills in practice both during and after the course. All questions were deliberately open-ended as to invite stories and examples rather than direct answers to questions. Moreover, the questions were formulated in such a way that they avoided directly asking how the participants experienced the authenticity of the course. This approach was chosen to avoid affecting the responses: the participants were aware that the authentic e-learning framework was used in the program and the researcher did not want them to think there were preferred answers.

Since the research task involved examining the experience of authenticity, a thematic analysis framework was constructed using the nine elements of authentic learning for the initial categorisation of the data. The respondents' written survey answers and excerpts from the transcribed interviews were first arranged into the nine categories, according to the element of authentic learning relevant for the response. In some cases, the responses were arranged into more than one category. This was followed by sorting the categorised excerpts into challenges and successes regarding each given element, depending on the nature of the experience described by the respondents. Once all the responses were categorised, recurring themes were sought through a coding process and the excerpts were further arranged thematically. To enable a closer examination of how the technologies used in the course affected the learning experience, a further thematic analysis was conducted with regard to the use of technologies in the course. The two sets of analysed data were then combined to find out how the use of different technologies in the learning design supported or hindered the participants' experience of authenticity with regard to specific elements of authentic learning. In the following section, the findings in each category of the thematic analysis framework are introduced.

\section{Findings of the study: successes and challenges}

\section{Authentic context}

The findings of the study suggest that the participants had a very positive experience with the authentic context. Two major themes emerge from the data. Firstly, the participants frequently emphasised that the course content was authentic. They pointed out that the learning material was based on real vaccine supply chain and environments, the way it was presented through the EPELA environment followed the authentic processes and sequences of events and it was supported with proper procedures and paperwork. Secondly, things learned were relevant and encouraged application. Expressions such as "extremely relevant”, "real life", and "realistic" were very frequent in the responses. The participants appreciated that the learning context was similar to their actual working contexts. As one of the participants put it: "it was something we work with every day”.

Technologies that especially supported the formation of an authentic context were the VVM cards, the videos and the EPELA environment. All the participants praised the ability to observe real VVMs and they felt there was a strong contrast between this practical learning experience and many previous experiences with e-learning:

Like, the VVMs were real VVMs. The observation task where we put the VVM cards under the table, the freezer, the drawer, and you observe it for several days, which is different from the other e-learning courses which are - you know more, you can say theoretical. In this we have the two: theory and really practice.

Several participants also found the videos extremely helpful in terms of understanding what the authentic environment is like.

There were very few challenges associated with the authentic context. Only one particular response could be categorised as problematic; however, it is noteworthy as it clearly illustrates the significance of an authentic context for a meaningful professional learning experience. One participant found one particular topic too "theoretical" and struggled with relating the topic to practice. This led to a lower level of enjoyment and a less successful learning experience compared to all the other topics that the participant 
described as highly relevant. This finding highlights the importance of ensuring that all topics covered in a professional development experience are clearly related to practice and their relevance becomes clear to all participants.

\section{Authentic tasks}

The respondents identified the authentic task as one of the main factors that differentiated the e-VVM learning experience from their previous e-learning experiences. Three central themes emerged from the data: authentic tasks were enjoyable, they promoted deep learning and they encouraged commitment to the learning process. Many participants highlighted the final task of the course where they worked as investigators with an actual real-world case as one of the most powerful learning experiences they had and as one that developed real-world skills. As one of the participants pointed out, "now I think I know how I would do that investigation". The participants appreciated the hands-on learning approach throughout the course and found it extremely beneficial for learning outcomes. These words of a participant summarise it aptly:

If somebody tells you, you may just listen; you might not pay so much attention to some of it. But when you're doing it yourself, you are observing it. We did the observations ourselves. We did the documentation ourselves. So it sits in our heads!

The single most significant challenge with regard to the authentic tasks was related to scheduling one's work and proceeding with the task within the required timeframe. The e-VVM course is quite intensive and requires a 9-week period of commitment without a break. Several participants reported on time constraints they faced due to other commitments, such as busy schedule at work, family responsibilities, work-related travel to remote areas with limited or no Internet connection, as well as unexpected circumstances, for example, illness. Although everyone felt that the study period was intensive, there were two different ways of responding to this. Some participants feared that the quality of their work suffered from the busy schedule, whereas surprisingly many found that the intensity actually encouraged them to do their very best and pushed them to commit to the studies more fully.

\section{Access to expert performances}

In adult learning, not only the mentors, but also the participants themselves bring in a tremendous amount of experience. Experience has been seen as one of the richest resources for adult learning that provides an appropriate starting point for learning activities (Knowles, 1990). However, tapping into this resource does not take place automatically but it must be supported and encouraged by the learning design, tasks and facilitation. The findings of this study indicate that the participants found the opportunity to learn from each other's expertise as one of the most beneficial aspects of the e-VVM course. These opportunities were facilitated by technologies such as the discussion forums and Skype conferences that encouraged the participants to share their expertise and experiences with each other. The fact that the participants all worked in different countries and environments provided a unique learning experience through access to expert performances in different contexts. As a participant states, "these were great people who have great insight in their own environments, something we could learn from.”

Learning from mentors' expertise was another form of this element that could be detected in the data. Expert videos were produced carefully to minimise the didactic nature of lecturing, mostly explaining the facts with live examples from different parts of the world as well as with humour. In addition, this type of learning seemed to occur in a more dialogic way, through Skype connections and discussions and in the form of feedback.

The challenges associated with access to expert performances were again related to the intensive schedule of the course. Some participants would have welcomed more informal discussions with colleagues but the busy schedule left little time for non-compulsory activities.

\section{Multiple perspectives}

Herrington et al. (2010) point out that examining a problem and accumulating practice from a single perspective are not sufficient to ensure expertise. Therefore, OPD should provide different perspectives 
and the opportunity to criss-cross the learning environment and resources instead of presenting the course in a linear instructional format. The participants of the e-VVM course appreciated the different perspectives offered by the diversity of resources as well as the diversity of participants. However, there were also challenges associated with both of these. Although the participants had the chance to explore the learning environment and access multiple resources, some expressed their frustration with the lack of time to properly familiarise themselves with them. Similarly, some would have welcomed more opportunities to learn from the different perspectives brought in by their peers and found it was constrained by the busy schedule:

I would say, initially, before we started getting lots of assignments, the discussion was pretty lively. There was people contributing their views, alive, civilised debate going back and forth ... there was kind of wavering off that kind of dialogue because we were just all really busy.

\section{Collaborative construction of knowledge}

Collaborative construction of knowledge, especially in online learning, is easier said than done. This element turned out to be one of the most challenging aspects of the course for some, and one of the most rewarding aspects for others. Although all participants engaged in the same collaborative tasks, some of the groups were more successful in actually constructing knowledge collaboratively than some other groups. The final task (a case study where students compiled a report and presented it to a real client) was a good example of this. Some groups had worked collaboratively, using a range of communication technologies to discuss, brainstorm and iterate their work, taking advantage of the expertise of the group members and learning from each other. One of the participants describes this process as follows:

I and my partner we actually did a lot of work on the case study and the presentation as well. We put in our very best. It was a very good one. I mean, my partner was also in a different country, we were working online, we did the case study and the presentation ... and we never met. That was the first time for me doing something like this ... working with people from different continents, and we were able to work simultaneously.

Some others, however, had resorted to simple cooperation rather than collaboration. In these cases, collaborative construction of knowledge was not attained as intended in the learning design. Several reasons for this could be found in the data. The challenges were not dissimilar to challenges typically associated with any collaborative activities, be it online or face-to-face. Such themes were uneven distribution of work and communication issues that some participants experienced within their teams. Moreover, scheduling of collaborative work was sometimes challenging. The participants were juggling between commitments and at times this showed in their collaborative tasks, partly explaining the first two challenges. Additionally, many of the participants had no previous experience with online collaborative learning, which may also have resulted in the challenges discussed above.

On the other hand, many participants enjoyed collaborative learning, particularly as it enabled learning from others and increased motivation and commitment. As one of the participants mentioned, "we had some complex collaborative tasks with colleagues from different countries. So we're dealing with, you know, actual tasks." Some also mentioned a sense of accountability and responsibility that stemmed from the collaborative work. A remarkable demonstration of motivation and commitment was that for some participants, collaborative construction of knowledge extended beyond course expectations both during and after the course:

The course is over but there's a couple of us that are still communicating and digesting... we take a scenario and we kind of change it a little bit, and add our own experiences we used to deal with ... like, OK, this is similar to, but if you add this, this and this ... that's kinda what we do.

Two design features that were found to promote and facilitate collaborative construction of knowledge were good course management and facilitation and good communication strategies and flexible use of technology. The participants mentioned small and rotating groups as examples of measures that reduced the challenges associated with collaboration. The role of technology in facilitating collaboration was 
central. The most successful groups were not restricted to the technologies introduced in the course but communicated flexibly with technologies suitable for them, for example, Facebook and WhatsApp.

\section{Reflection}

The data suggests that authentic context and tasks promoted reflection. The participants found that the way the materials and tasks were presented encouraged them to reflect on their learning, contemplate possible solutions and think about their actions. Herrington et al. (2010) believe that in order for an elearning course to enable meaningful reflection, it should provide an authentic context and task, as well as a non-linear organisation to allow for students to return to different elements if desired.

The biggest challenge associated with reflection was, again, the busy schedule. Some participants felt that there was not enough time to digest and reflect. As one participant mentioned, "when you finished a task you were already faced with a new task, so you couldn't reflect too much". Some would also have welcomed more time for collaborative reflection; however, as already mentioned in connection with multiple perspectives, the dialogue in the discussion boards slowed down as the participants became more occupied with the tasks.

\section{Articulation of one's growing knowledge}

The use of a wide selection of collaborative technologies was found to have a positive impact on the authentic learning element of articulation. An interesting finding was that having an authentic audience was motivating and improved quality of learning. The ability to share learning products with the group rather than merely submitting them to the teaching team was appreciated by the participants. The responses reveal that meaningful articulation took place in written form in discussion forums, through Flipgrid videos, as well as through synchronous online presentations. The ability to comment and discuss each other's work was welcomed:

Using the technology, you could see other people's work and they could see your work. Then you could comment. Like, when you got comments, I took them positively in such a way that it improved my knowledge. When I do my own work, maybe someone did better than I did, and then I would learn from that.

People were commenting and I was so excited. And I was also replying to the comments. So it made it very interesting for me.

\section{Scaffolding and coaching}

Many e-learning designs are based on self-contained resources and individual learning. Authentic e-learning differs from these approaches in that mentors have very important roles in the learning process. However, instead of direct instruction, mentors provide expert assistance in the form of feedback, critical questions, suggestions and hints that help the learners to solve problems of increasing complexity (Herrington et al., 2010). The participants of the e-VVM course generally had a very positive experience with scaffolding and coaching. Two themes that emerged from the data were the value of prompt and helpful feedback as well as availability of mentors. Many participants gave detailed descriptions of the type of feedback they had received and explained how it had helped them to understand and challenged them to apply. Moreover, the mentors had been available to answer questions without delay, both via email and Skype. No one had any complaints in this regard, and challenges related to scaffolding and coaching were very few. One person had hoped for a more direct instruction and correction at points. This is, after all, the teaching style many learners may expect, as it is what they are accustomed to.

\section{Authentic assessment}

The e-VVM course does not involve assessment in the traditional sense of testing learning and giving grades. Instead, assessment is based on completing the authentic tasks and participating actively in the learning process. Thus, it is not surprising that the experiences with authentic assessment in the e-VVM course go hand in hand with authentic tasks and collaborative construction of knowledge. There were two major themes related to the successes: authentic tasks promoted application of knowledge and shared 
products promoted learning from others. The most significant challenge that was identified was related to time constraints and scheduling.

\section{The role of technology}

Despite the versatility of the technologies introduced in the e-VVM course, none of the participants reported any difficulty in learning to use these tools. On the contrary, many listed a selection of other tools that they had chosen to use in addition to the required technologies, such as WhatsApp and Facebook. Three primary ways the technologies impacted on the experience of authenticity could be detected:

(1) Technologies enabled the creation and sharing of an authentic context.

(2) Technologies facilitated the collaboration and completion of authentic tasks.

(3) Technologies were actively used for communication and building a learning community.

There were also challenges associated with the use of technology. These fell into two main categories of what we refer to as technology barriers. The most frequently encountered ones were accessibility barriers. Many of the participants worked in rural and remote areas in developing countries and had sporadic or limited access to the Internet. This barrier affected especially the technologies that require ample bandwidth, such as videos. However, the issue was often tackled by reverting to voice only when using Skype, downloading instead of streaming, forwarding mobile standard definition versions of the videos and using alternative methods of communication, typically with mobile phones (e.g., WhatsApp, SMS). Another challenge was usability issues that some participants encountered with some of the technologies. These were tackled by sharing tips and tricks and by guidance from mentors. The second category consisted of pedagogical barriers. Some participants were not always able to see the relevance of a given technology to the task or find it pedagogically meaningful. As a result, some chose not to engage with given technologies, or they would only do the bare minimum that was required. This highlights the importance of ensuring that not only the tasks and learning materials, but also the use of technology is authentic and relevant for the learners.

\section{Discussion and conclusion}

The aim of the present study has been to find out whether and in what ways the intended authenticity of the e-VVM course that was sought with the authentic e-learning design and the use of education technologies was translated into an attained sense of authenticity from the perspective of the participants. The findings indicate that the participants had a strong sense of authenticity in the course, which implies that the elements of authentic learning together with meaningful use of technology provide a highly useful design framework for OPD. Contrary to some earlier perceptions of e-learning, our observations suggest that online education technologies can be used to create an authentic learning environment where practical, transferable professional skills can be acquired. The responses of the participants frequently emphasised the high practical relevance of the course content as well as the benefits of active learning by doing, observing, collaborating and solving problems. It is also noteworthy that some of the participants were so motivated that they chose to continue to collaborate in self-directed, non-formal learning after the course. In the light of these findings it seems that the participants experienced authenticity during the course, and that at least in some aspects the course resulted in social, active and practice-driven professional learning (Webster-Wright, 2009).

The authentic learning framework provides a starting point to the learning design that differs significantly from the traditional online learning designs based on providing content and activities in manageable chunks, organised in a linear format and presented in a consistent template (see, e.g., Martin, 2011). In authentic learning, the emphasis is on the authentic tasks that deliberately maintain the complexity and open-endedness characteristic to real-world problems. Education technology is also used in a different way: the authenticity is promoted by using technology as cognitive tools for problem-solving, collaborating and constructing knowledge.

Contrary to common beliefs that requiring the participants to become familiar with a variety of technological tools should be avoided in an online course, the experiences of the participants suggest that the versatile use of social technologies contributed to the experience of authenticity. Although many of 
the participants were not new to online learning, many of the technologies used in the course were new to them. The findings suggest that lack of experience with the technologies and even accessibility are barriers that can be overcome. Patience, courage and flexibility are required from both the participants and the mentors, but it pays off, as the participant comments indicate ("it was like magic", "you know... it was real!”). Resorting to a learning management system used primarily for content delivery and keeping the number of other tools to a minimum would have deprived the participants of some of the authentic learning experiences they gained. However, when introducing many technologies, it is crucial to ensure that accessibility issues are dealt with, and that the participants find the tools serving a clear purpose in the authentic task.

One of the most interesting findings of the study was the significant role of the scheduling and the impact it had on the experience of authenticity. The e-VVM course does not fit in the description according to which "online learning provides flexibility for adult learners to engage in and complete learning programs at times which suit them” (Michinov, Brunot, Le Bohec, Juhel, \& Delaval, 2010, p. 244). In a cohortbased collaborative learning context a defined schedule is a necessity. However, learners may respond to it in different ways. In the e-VVM course, the scheduling seemed to create a dilemma: the intensive nature of the studies promoted commitment to the authentic tasks, while at the same time it was perceived by some participants to reduce the opportunities for discussion and reflection. It is, however, interesting to find that the intensive schedule challenged and encouraged many participants to participate actively and do their best. Time management skills have been found to be essential in online learning programs and high procrastination has been identified as a predictor of poor performance (Michinov et al., 2010). Active participation in online interaction is another factor that predicts learning effectiveness: Davies and Graff (2005) found that students who failed their online courses tended to interact less frequently with others than the ones who received passing grades. The relatively intensive schedule and authentic collaborative tasks of the e-VVM course may have had a positive impact on active participation. The willingness to commit to studies and do one's very best is something every educator would love to see in their students, yet, as Reeves (2006) points out, the conative learning domain is often ignored by instructors. The conative domain is associated with action and it focuses on the act of striving to perform at the highest levels (Reeves, 2006), or, as Huitt (1999, ๆ 3) describes it, it is the "personal, intentional, planful, deliberate, goal-oriented, or striving component of motivation”. Ruohotie (1999) adds to this persistence, willingness to learn and commitment to the study process. Despite the importance of these skills, research into online learning designs that intentionally aim to support the development of them is scarce.

The authentic learning principles and the use of technology as cognitive tools can be seen as a promising approach to designing fully online, but highly social, active and practice-driven professional development that is also appreciated and perceived as authentic by the participants. It seems that such a learning design may promote the use of conative skills, as exemplified by the participants' willingness to do their best, invest considerable time and effort and even go beyond course expectations in collaborative learning. This observation provides an interesting and relevant topic for further research.

\section{References}

Anderson, L. W., Krathwohl, D. R., \& Bloom, B. S. (2001). A taxonomy for learning, teaching, and assessing: A revision of Bloom's taxonomy of educational objectives. New York, NY: Longman.

Baran, B., \& Cagiltay, K. (2006). Teachers' experiences in online professional development environment. Turkish Online Journal of Distance Education, 7(4), 110-122. Retrieved from http://tojde.anadolu.edu.tr/makale_goster.php?id=300

Bates, M. S., Phalen, L., \& Moran, C. (2016). Online professional development a primer: Educators have access to a dizzying array of virtual learning opportunities, but they must be mindful that working with colleagues produces some of the best learning. Phi Delta Kappan, 97(5), 70-73. doi:10.1177/0031721716629662

Bloom, B. S., Engelhart, M. D., Furst, E. J., Hill, W. H., \& Krathwohl, D. R. (1956). The taxonomy of educational objectives: Handbook 1, Cognitive domain. New York, NY: David McKay.

Bozalek, V., Gachago, D., Alexander, L., Watters, K., Wood, D., Ivala, E., \& Herrington, J. (2013). The use of emerging technologies for authentic learning: A South African study in higher education. British Journal of Education Technology, 44(4), 629-638. doi:10.1111/bjet.12046 
Bradley, J. B., Rachal, J., \& Harper, L. (2014). Online professional development for adults: Utilizing andragogical methods in research and practice. In Information Resources Management Association USA (Ed.), Adult and continuing education: Concepts, methodologies, tools and applications (pp. 396-418). Hershey, PA: IGI Global.

Brown, J. S., Collins, A., \& Duguid, P. (1989). Situated cognition and the culture of learning. Educational Researcher, 18(1), 32-42. doi:10.3102/0013189X018001032

Davies, J., \& Graff, M.G. (2005). Performance in e-learning: Online participation and student grades. British Journal of Education Technology, 36(4), 657-663. doi:10.1111/j.1467-8535.2005.00542.x

Garet, M. S., Porter, A., Desimone, L., Birman, B. F., \& Yoon, K. S. (2001). What makes professional development effective? Results from a national sample of teachers. American Educational Research Journal, 38(4), 915-945. doi:10.3102/00028312038004915

Gulikers, J. T. M., Bastiaens, T. J., \& Kirschner, P. A. (2004). A five-dimensional framework for authentic assessment. Educational Technology, Research and Development, 52(3), 67-86. doi:10.1007/BF02504676

Gulikers, J., Bastiaens, T., Kirschner, P. A., \& Kester, L. (2008). Authenticity is in the eye of the beholder: Student and teacher perceptions of assessment authenticity. Journal of Vocational Education and Training, 60(4), 401-412. doi:10.1080/13636820802591830

Herrington, J., \& Oliver, R. (2000). An instructional design framework for authentic learning environments. Educational Technology Research and Development, 48(3), 23-48. doi:10.1007/BF02319856

Herrington, J., Reeves, T. C., \& Oliver, R. (2010). A guide to authentic e-learning. London: Routledge.

Huitt, W. (1999). Conation as an important factor of mind. Educational Psychology Interactive. Valdosta, GA: Valdosta State University. Retrieved from http://www.edpsycinteractive.org/topics/conation/conation.html

Husnin, H., Din, R., Karim, A., Norman, H., \& Hamdan, A. (2013). Assessing authentic learning via storyboarding: A Malaysian perspective. Asian Social Science, 9(16), 46-53. doi:10.5539/ass.v9n16p46

Jonassen, D. H., \& Reeves, T. C. (1996). Learning with technology: Using computers as cognitive tools. In D. H. Jonassen (Ed.), Handbook of research on educational communications and technology (pp. 693-719). New York, NY: Macmillan.

Knowles, M. (1990). The adult learner: A neglected species (4th ed.). Houston, TX: Gulf Publishing.

Kolb, D. (1984). Experiential learning: Experience as the source of learning and development. Englewood Cliffs, NJ: Prentice-Hall.

Kyalo, I. W., \& Hopkins, S. (2013). Exploring the acceptability of online learning for continuous professional development at Kenya medical training colleges. Electronic Journal of e-Learning, 11(2), 82-90. Retrieved from http://www.ejel.org/volume11/issue2

Liu, K. Y. (2012). A design framework for online teacher professional development. Asia Pacific Education Review, 13(4), 701-711. doi:10.1007/s12564-012-9230-0

Martin, F. (2011). Instructional design and the importance of instructional alignment. Community College Journal of Research and Practice, 35(12), 955-972. doi:10.1080/10668920802466483

Michinov, N., Brunot, S., Le Bohec, O., Juhel, J., \& Delaval, M. (2011). Procrastination, participation, and performance in online learning environments. Computers \& Education, 56(1), 243-252. doi:10.1016/j.compedu.2010.07.025

Petraglia, J. (1998). The real world on a short leash: The (mis)application of constructivism to the design of educational technology. Educational Technology Research and Development, 46(3), 53-65. doi:10.1007/BF02299761

Petraglia, J. (2009). The importance of being authentic: Persuasion, narration and dialogue in health communication and education. Health Communication, 24(2), 176-185. doi:10.1080/10410230802676771

Reeves, T. C. (2006). How do you know they are learning?: The importance of alignment in higher education. International Journal of Learning Technology, 2(4), 294. doi:10.1504/IJLT.2006.011336

Ruohotie, P. (1999). Oppiminen ja ammatillinen kasvu [Learning and professional development]. Helsinki: WSOY.

Salmon, G., \& Wright, P. (2014). Transforming future teaching through ‘Carpe Diem’ learning design. Education Sciences, 4(1), 52-63. doi:10.3390/educsci4010052

Valtonen, T., Kukkonen, J., Kontkanen, S., Sormunen, K., Dillon, P., \& Sointu, E. (2015). The impact of authentic learning experiences with ICT on pre-service teachers' intentions to use ICT for teaching and learning. Computers \& Education, 81, 49-58. doi:10.1016/j.compedu.2014.09.008 
Van den Akker, J. (2003). Curriculum perspectives: An introduction. In J. Van den Akker, W. Kuiper, \& U. Hameyer (Eds.), Curriculum landscapes and trends. (pp. 1-10) Dordrecht: Kluwer.

Vesper, J., Herrington, J., Kartoğlu, U., \& Reeves, T. C. (2015). Initial design principles for establishing a learning community for public health professionals through authentic e-learning. International Journal of Continuing Engineering Education and Lifelong Learning, 25(2), 241-257. doi:10.1504/IJCEELL.2015.069870

Webster-Wright, A. (2009). Reframing professional development through understanding authentic professional learning. Review of Educational Research, 79(2), 702-739. doi:10.3102/0034654308330970

World Health Organization. (2002). Getting started with vaccine vial monitors. Geneva: Author. Retrieved from http://apps.who.int/iris/bitstream/10665/67806/1/WHO_V-B_02.35_eng.pdf

Yeoman, I. (2012). Authentic learning: My reflective journey with postgraduates. Journal of Teaching in Travel \& Tourism, 13(3), 295-311. doi:10.1080/15313220.2012.704258

Yin, R. K. (1999). Enhancing the quality of case studies in health services research. Health Services Research, 34(5), 1209-1224. Retrieved from https://www.ncbi.nlm.nih.gov/pmc/articles/PMC1089060/

Yin, R. K. (2013). Validity and generalisations in future case study evaluations. Evaluation, 19(3). 321332. doi:10.1177/1356389013497081

Corresponding author: Hanna Teräs, hanna.teras@murdoch.edu.au

Australasian Journal of Educational Technology (C) 2018.

Please cite as: Teräs, H., \& Kartoğlu, Ü. (2018). Authentic learning with technology for professional development in vaccine management. Australasian Journal of Educational Technology, 34(3), 15-29. https://doi.org/10.14742/ajet.2815 